Article

\title{
Temporal Variation of Water Environment Carrying Capacity in a Highly Urbanized Region of China
}

\author{
Zhiqing $X u^{1,2}$, Shuhu Xiao ${ }^{1,3,4}$, Cong Du ${ }^{1,3,4, *}$, Qiyu Deng ${ }^{1,3}$, Bingfei Yan ${ }^{1,3}$, Zhiwen Zeng ${ }^{3}$ \\ and Xueyu Liu ${ }^{1,3, *}$ \\ 1 State Key Laboratory of Environmental Criteria and Risk Assessment, Chinese Research Academy of \\ Environmental Sciences, Beijing 100012, China; langi90@163.com (Z.X.); Xiaoshuhu@126.com (S.X.); \\ u---i@126.com (Q.D.); ybf2015@163.com (B.Y.) \\ 2 Nanchang Municipal Ecology and Environment Bureau, Nanchang 330038, China \\ 3 Institute of Water Ecology and Environment, Chinese Research Academy of Environmental Sciences, \\ Beijing 100012, China; 18848957172@163.com \\ 4 State Environmental Protection Key Laboratory of Estuarine and Coastal Environment, \\ Chinese Research Academy of Environmental Sciences, Beijing 100012, China \\ * Correspondence: ducongducong@126.com (C.D.); Liuxueyu@craes.org.com (X.L.); \\ Tel.: +86-10-8492-8381 (C.D. \& X.L.)
}

Received: 13 October 2020; Accepted: 20 November 2020; Published: 30 November 2020

\begin{abstract}
China has experienced an unparalleled urbanization process in recent decades, which has dramatically changed the water environment. Quantification of the water environment carrying capacity (WECC) is crucial given its importance to sustainable development. Existing studies have typically focused on the overall WECC system and lacked analysis of its internal features. In this study, the concepts, calculations, and classifications of the WECC were further developed. Using Nanjing, China, as a case study, we developed a hierarchical evaluation indicator system including three system layers (social, environmental and economic subsystems). We applied the entropy weight and fuzzy comprehensive evaluation method to evaluate the temporal variation tendency of WECC, and explored the deep-seated problems stemming from urbanization. The results indicated that WECC in Nanjing was 0.3045-0.5302 during 2006-2017, thus approaching a moderate grade with a relatively slow growth rate. Social, environmental, and economic subsystems increased by $29.3 \%, 83.1 \%$, and $97.2 \%$, respectively. Overall, Nanjing had a solid foundation regarding its economic subsystem, but its social and environmental subsystems were under pressure. Factors such as slow population growth as well as reduced energy and water use intensity improved WECC, whereas factors such as increased population density and excessive water consumption blocked WECC. Practical suggestions were proposed to resolve the primary problems of the WECC under urbanization. This holistic approach is urgently needed to achieve water environmental sustainability, both for Nanjing and for other emerging cities.
\end{abstract}

Keywords: water environment carrying capacity; entropy weight; fuzzy comprehensive evaluation; Nanjing City

\section{Introduction}

Urbanization has been increasing globally, especially in developing countries, and is characterized by high population densities [1]. Human activities, especially in megacities, have led to a fast-growing economy and a rapidly developing society but have also caused various environmental problems worldwide [2]. One of the most severe environmental impacts is the deterioration of water quality, which can lead to an imbalance in river ecosystems, while concurrently threatening socioeconomic 
sustainability [3]. At present, the conflict between economic development and water environment protection is becoming increasingly intense [4]. This is especially true in rapidly growing large cities in developing countries [5]. To provide guidance for policy makers in sustainable development, a scientific method that can measure progress towards coordinated development of the economy and the water environment is an urgent requirement.

Water environment carrying capacity (WECC) is often used to assess sustainable socio-ecological development. It can be defined as "the largest population and economic scale that the water environment can support in a specific region during a period of time without an adverse impact on the local water environment" [6]. In the late 1960s and the early 1970s, a carrying capacity problem of the environment was noted when resource depletion and environmental degradation caused by rapid growth of the population and the economy began receiving attention [7,8]. In the early 1980s, the concept of WECC was proposed when the management of the water environment became increasingly important for ecosystem health and human health, as the impacts of human activities were further exacerbated [9]. Subsequently, based on a profound understanding of the mutual relationships between socio-economic development and the water environment, the carrying capacity of the environment has been further studied since the 1990s [10]. At present, most studies have integrated the carrying capacity theory into sustainable development research $[6,11,12]$. Wang et al. made policy recommendations to guarantee sustainable utilization of water resources, based on analysis of the wetland water resources carrying capacity in Beijing city [13]. Jia et al. provide a scientific reference to the management of sustainable economic and social development in China according to the spatial similarities and variations of the WECC [14]. Meng et al. regarded environmental carrying capacity as one of their sustainable development categories [15]. Peng and Deng calculated the resource carrying capacity of Guiyang from 2003 to 2017, in order to put forward corresponding countermeasures for sustainable development [16]. WECC has become an important means for assessing whether the social economy coordinates with water environment systems, and it plays a crucial role in helping cities to make informed decisions concerning sustainable development.

Most previous studies have focused on quantitative analyses of WECC using different evaluation approaches [17]. These methods include comprehensive evaluation methods, ecological footprints, and multi-objective programming [18-20]. In recent years, more methods have been developed to evaluate carrying capacity including the BP (Back Propagation) neural network algorithm, matter element analysis method, and a grid search method based on GIS (Geographic Information System) [21,22]. Among these, comprehensive evaluation methods are commonly used to evaluate WECC. These methods can combine many individual indicators into a single comprehensive index. Comprehensive evaluation methods can be classified into four primary types: fuzzy comprehensive evaluation, analytic hierarchy process (AHP), principal component analyses (PCA), and the system dynamics method (SD). Lu et al. studied WECC in Huai'an from 2005 to 2014 using AHP [23]. Zhang et al. applied PCA to evaluate temporal variation trends in the water resources-water environment carrying capacity from 2005 to 2015 [24]. Yang et al. constructed a multi-criteria evaluation system of water resources carrying capacity for Xi'an to predict the developmental trends from 2015 to 2020 by SD models [25]. AHP allocates weights by allowing experts to evaluate the relative importance of indexes in pairs, which makes it more subjective than other methods. PCA can turn an original dataset into principal components, but the principal components are not as readable and interpretable as the original dataset. SD requires a substantial amount of historical data, such as population, pollution emission and other socio-economic information, thus has not been widely used due to higher costs and difficulties in data acquisition.

At present, the main challenge facing WECC evaluation is the fuzziness and uncertainty of carrying capacity and the complicated relationships between indicators and WECC [26]. The aforementioned three methods cannot efficiently handle the uncertainty and ambiguity of the evaluation process. To solve this problem, we proposed a fuzzy comprehensive evaluation method based on entropy weight. Fuzzy comprehensive evaluation method uses the fuzzy logic theory and membership function 
to make an overall evaluation of complicated items affected by multiple factors [27,28]. For this method, the characteristics of each influential factor are considered comprehensively, and fuzziness or uncertainty in WECC evaluation can be efficiently tackled, which makes the evaluation process more accurate and reliable.

As for the assignment of indicator weights, there are two current primary weighting methods: subjective weighting and objective weighting. The entropy weight method is typically representative of objective weighting methods, which depends excessively on the objective data of indicators [29]. Therefore, to avoid the weights affected by researchers' perception, the entropy weight method was applied in this research.

As the largest developing country, China has experienced both rapid urbanization and prosperous economic growth in recent decades. The proportion of the urbanized population is expected to increase at an unprecedented rate in the upcoming decades, thereby increasing the importance of WECC evaluations in ensuring sustainable development. To better understand the changes in WECC, it is necessary to obtain accurate information about the performance of indicators. In this study, we selected Nanjing City as a test case because this area has been highly urbanized in recent years. Our objectives were to: (1) establish an evaluation indicator system for WECC; (2) detect the temporal dynamics of WECC for the 2006-2017 period, (3) provide the first quantification of the changes in indicators to identify the improving and blocking factors of WECC via the fuzzy comprehensive evaluation method, and (4) identify problems and provide suggestions for promoting the regional WECC. The results of the present study can provide important guidance for improving WECC and may be of considerable importance to further work on sustainable development both in China and in other countries.

\section{Materials and Methods}

\subsection{Study Area}

The study was performed in Nanjing (Figure 1). Nanjing $\left(118^{\circ} 22^{\prime \prime}-119^{\circ} 14^{\prime \prime} \mathrm{E} ; 31^{\circ} 14^{\prime \prime}-32^{\circ} 37^{\prime \prime} \mathrm{N}\right)$, the capital city of Jiangsu Province, is situated in the eastern part of China. It has a total population of 8.30 million and an area of $6587 \mathrm{~km}^{2}$. The region has a subtropical monsoon climate with an average annual temperature of $15.4{ }^{\circ} \mathrm{C}$ and rainfall of $1106 \mathrm{~mm}$. Within the city limits, more than $11 \%$ of the area is occupied by water. The Yangtze River flows through Nanjing, and exits the city to the northeast, thus its water quality is exceedingly important to downstream cities such as Shanghai.

The urbanization rate of Nanjing increased from $76.4 \%$ in 2006 to $82.1 \%$ in 2017, while an urbanization rate of more than $70 \%$ is defined as highly urbanized in the "City Blue Book: China Urban Development Report no.12" published in 2019. The GDP of Nanjing reached 170.2 billion dollars, and the per capita GDP has been 20,508 dollars since 2017; both values are above the average statistics for moderately developed countries. The regional urbanization rate is $82 \%$ and has reached a mature stage. Nanjing supports important heavy industrial activities (petrochemical production, electricity generation, steelmaking, and shipbuilding) that account for poor water quality in many rivers. Additionally, rapid population expansion in recent decades has also increased wastewater discharge. Over 30 plants are distributed throughout Nanjing to treat municipal and industrial wastewater using different approaches. These statistics are mainly from the Nanjing statistics yearbook. 


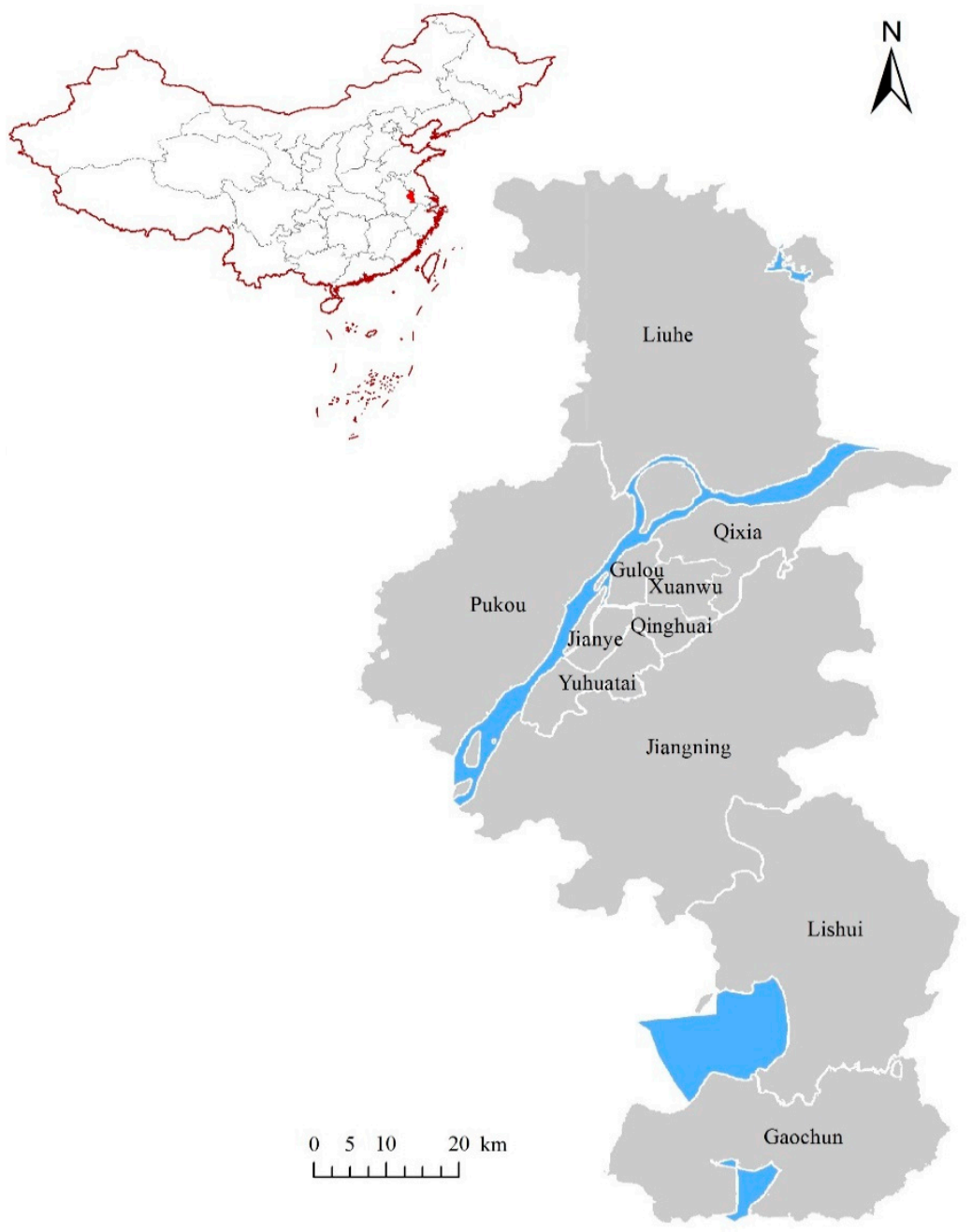

Figure 1. Administrative map of Nanjing.

\subsection{Construction of Evaluation Indicator System}

Identifying an appropriate indicator evaluation system is crucial for WECC, as it can determine whether the current water environment is sustainable and, if not, how to address its underlying problems. A hierarchical evaluation indicator system for WECC has been established in this paper based on the study of the relationship between environmental quality, water resources and social economy $[30,31]$. In this evaluation system, the overall target is represented by $\mathrm{A}$ and the overall goal is further divided into three system layers, including social subsystem $\left(A_{1}\right)$, environmental subsystem $\left(\mathrm{A}_{2}\right)$, and economic subsystem $\left(\mathrm{A}_{3}\right)$.

When selecting indicators, those frequently used in relevant studies were first clarified by the frequency statistical method. Secondly, the indicators related to social, environmental and economic studies were extracted. Thirdly, each indicator was vetted specifically against the following selection principles: accessibility, feasibility of measurement, relevance in assessing the water environment, whether the indicator was within governmental capabilities for development, and whether it was representative of the related issues to the greatest possible extent [32]. Finally, 23 indicators were selected in the evaluation system, as shown in Table 1. 
Table 1. Evaluation indicator system of water environment carrying capacity (WECC).

\begin{tabular}{|c|c|c|c|c|}
\hline Overall Target & System Layer & Indicator Layer & Units & Attributes \\
\hline \multirow{23}{*}{$\begin{array}{c}\text { water } \\
\text { environment } \\
\text { carrying } \\
\text { capacity(A) }\end{array}$} & \multirow{5}{*}{$\begin{array}{l}\text { Social } \\
\text { subsystem }\left(\mathrm{A}_{1}\right)\end{array}$} & Population growth rate $\left(u_{1}\right)$ & $\%$ & - \\
\hline & & Population density $\left(u_{2}\right)$ & people $/ \mathrm{km}^{2}$ & - \\
\hline & & Urbanization rate $\left(u_{3}\right)$ & $\%$ & + \\
\hline & & Domestic water use per capita $\left(u_{4}\right)$ & $\mathrm{L} /($ day $\cdot$ person $)$ & - \\
\hline & & Industrial water reuse $\left(u_{5}\right)$ & $\%$ & + \\
\hline & \multirow{10}{*}{$\begin{array}{l}\text { Environmental } \\
\text { subsystem }\left(\mathrm{A}_{2}\right)\end{array}$} & Water resources per capita $\left(u_{6}\right)$ & $\mathrm{m}^{3} /$ person & + \\
\hline & & Water resources utility rate $\left(u_{7}\right)$ & $\%$ & - \\
\hline & & Forest area as percent of land area $\left(u_{8}\right)$ & $\%$ & + \\
\hline & & Arable land area as percent of land area $\left(u_{9}\right)$ & $\%$ & + \\
\hline & & Use of fertilizers per unit of agricultural land area $\left(u_{10}\right)$ & $10^{3} \mathrm{~kg} / \mathrm{km}^{2}$ & - \\
\hline & & Use of pesticides per unit of agricultural land area $\left(u_{11}\right)$ & $\mathrm{kg} / \mathrm{km}^{2}$ & - \\
\hline & & Compliance rate for water quality standards $\left(u_{12}\right)$ & $\%$ & + \\
\hline & & Wastewater treatment rate $\left(u_{13}\right)$ & $\%$ & + \\
\hline & & COD emission per unit of industrial added value $\left(u_{14}\right)$ & $\mathrm{kg} / 10^{4} \mathrm{RMB}$ & - \\
\hline & & Wastewater discharge per unit of $\operatorname{GDP}\left(u_{15}\right)$ & $\mathrm{kg} / \mathrm{RMB}$ & - \\
\hline & \multirow{8}{*}{$\begin{array}{l}\text { Economic } \\
\text { subsystem }\left(\mathrm{A}_{3}\right)\end{array}$} & GDP per capita $\left(u_{16}\right)$ & $10^{4} \mathrm{RMB} /$ person & + \\
\hline & & Industrial output per capita $\left(u_{17}\right)$ & $10^{4} \mathrm{RMB} /$ person & + \\
\hline & & The percentage of tertiary industry $\left(u_{18}\right)$ & $\%$ & + \\
\hline & & Annual energy consumption per capita $\left(u_{19}\right)$ & $\mathrm{kg} /$ person & - \\
\hline & & Energy consumption per unit of $\operatorname{GDP}\left(u_{20}\right)$ & $\mathrm{kg} / 10^{4} \mathrm{RMB}$ & - \\
\hline & & Water consumption per unit of $\operatorname{GDP}\left(u_{21}\right)$ & $\mathrm{m}^{3} / 10^{4} \mathrm{RMB}$ & - \\
\hline & & Water consumption per unit of industrial added value $\left(u_{22}\right)$ & $\mathrm{m}^{3} / 10^{4} \mathrm{RMB}$ & - \\
\hline & & Generation of industrial solid waste $\left(u_{23}\right)$ & $10^{7} \mathrm{~kg}$ & - \\
\hline
\end{tabular}

Five indicators related to population, urbanization and water use have been chosen to represent the social subsystem situation. Population is an important contextual reference regarding WECC for decision makers evaluating the interrelationships between people, resources, and the environment. Rural-urban demographic transition increases pressure on the environment, especially in ecologically-sensitive areas. Moreover, most of the water used by industries and municipalities is often returned to watercourses degraded in quality, which makes water consumption a serious concern in environmental management.

Ten indicators reflecting the state of water resources, environmental pollution and protection are selected in the environmental subsystem. Adequate freshwater is essential to support the ecosystem and social and economic development. It also plays a pivotal role in human life, food production, industry, and hydropower generation. The quantity of available water is a measure of the vulnerability of a city to water shortages. In addition, land is becoming an increasingly scarce resource because of the expanding requirements of urban development. Many land-based issues such as agricultural land degradation, deforestation and desertification threaten the stability and resilience of water ecosystems. The use of agrichemicals while enhancing productivity also has potential impacts on the environment, including eutrophication and contamination of water supplies. Furthermore, four indicators focusing on sewage pollution and treatment are used in the subsystem, which can reflect ecosystem health and environmental governance, respectively.

Eight indicators concerning economic performance, energy use, and industrial waste generation are selected for this subsystem. Increasing economic growth and investment is critical for assisting cities in meeting the objectives of sustainable water environment. In addition, to improve the standard of living of a growing population, sharp increases in energy services will considerably compound future environmental and human health problems. Moreover, material consumption and waste production are also the major causes of the continued depletion of water resources and deterioration of the environment.

\subsection{Data Analysis}

In this study, the analysis consists of three steps: dimensionless standardization, weight calculation via entropy method, and fuzzy comprehensive evaluation. 


\subsubsection{Standardization of Raw Data}

To eliminate the influences of magnitude and dimension, it is necessary to standardize the raw data. The indicators with different attributes can be divided into positive and negative indicators, as shown in Table 1 . Then, all the indicators can be standardized by the following equations:

$$
\begin{aligned}
& y_{i j}=\frac{x_{i j}-\min \left(x_{i j}\right)}{\max \left(x_{i j}\right)-\min \left(x_{i j}\right)} \\
& y_{i j}=\frac{\max \left(x_{i j}\right)-x_{i j}}{\max \left(x_{i j}\right)-\min \left(x_{i j}\right)}
\end{aligned}
$$

where $x_{i j}$ is the original value of the $i$ th indicator in the $j$ th sample; $y_{i j}(i=1,2, \ldots, \mathrm{m}$, and $j=1,2$, $\ldots, n)$ is the standardized value of the $i$ th indicator in the $j$ th sample; and $m$ and $n$ are the number of indicators and samples respectively. Equation (1) is for positive indicators, whereas Equation (2) is for negative indicators.

\subsubsection{Entropy Weight Method}

Various indicators have different impacts on WECC and thus it is critical to attribute their weights. The entropy method was applied to ensure the objectivity and rationality of weight assignment [33]. In the equation below, $Y=\left(y_{i j}\right)_{m \times n}$ represents the standardized indicator matrix. The proportion $p_{i j}$ of the $i$ th indicator in the $j$ th sample to the total value of the $i$ th indicator was specified as follows:

$$
y_{i j}=\frac{\max \left(x_{i j}\right)-x_{i j}}{\max \left(x_{i j}\right)-\min \left(x_{i j}\right)}
$$

The entropy $e_{i}$ of the $i$ th indicator was calculated using the following function:

$$
e_{i}=-\frac{1}{\ln (n)} \sum_{j=1}^{n}\left(p_{i j} \ln \left(p_{i j}\right)\right)
$$

The weight $w_{i}$ of the $i$ th indicator was determined by the formula below:

$$
e_{i}=-\frac{1}{\ln (n)} \sum_{j=1}^{n}\left(p_{i j} \ln \left(p_{i j}\right)\right)
$$

\subsubsection{Fuzzy Comprehensive Evaluation}

Fuzzy comprehensive evaluation is a method that uses fuzzy set theory to convert the qualitative evaluation into a quantitative evaluation. The method has been applied to carrying capacity assessment to eliminate the fuzziness or uncertainty that may exist in the assessment process [34]. Furthermore, fuzzy comprehensive evaluation has now become an effective decision-making tool, especially in multi-factor assessments [35]. The main procedure of fuzzy comprehensive evaluation is as follows [36].

The factor set $U$ can be determined as:

$$
U=\left\{u_{1}, u_{2}, \cdots, u_{m}\right\}
$$

where $u_{i}$ is the $i$ th indicator value and $m$ is the number of indicators. 
The evaluation criteria set $V$ is the aggregate composed of three grading criteria, where $v_{1}, v_{2}$ and $v_{3}$ represents "excellent", "moderate" and "poor".

$$
V=\left\{v_{1}, v_{2}, v_{3}\right\}
$$

The following membership function was applied to determine the membership degree of each factor for three criteria.

$$
\begin{aligned}
& r_{1}\left(u_{i}\right)=\left\{\begin{array}{lr}
0.5\left(1+\frac{v_{1}-u_{i}}{v_{2}-u_{i}}\right) & u_{i}<v_{1} \\
0.5\left(1-\frac{u_{i}-v_{1}}{v_{2}-v_{1}}\right) & v_{1} \leq u_{i}<v_{2} \\
0 & u_{i} \geq v_{2}
\end{array}\right. \\
& r_{2}\left(u_{i}\right)=\left\{\begin{array}{lr}
0.5\left(1-\frac{v_{1}-u_{i}}{v_{2}-u_{i}}\right) & u_{i}<v_{1} \\
0.5\left(1+\frac{u_{i}-v_{1}}{v_{2}-v_{1}}\right) & v_{1} \leq u_{i}<v_{2} \\
0.5\left(1+\frac{v_{3}-u_{i}}{v_{2}-u_{i}}\right) & v_{2} \leq u_{i}<v_{3} \\
0.5\left(1-\frac{v_{3}-u_{i}}{v_{2}-u_{i}}\right) & u_{i} \geq v_{3}
\end{array}\right. \\
& r_{3}\left(u_{i}\right)=\left\{\begin{array}{lr}
0 & u_{i} \leq v_{2} \\
0.5\left(1+\frac{u_{i}-v_{3}}{v_{2}-v_{3}}\right) & v_{2} \leq u_{i}<u_{3} \\
0.5\left(1+\frac{v_{3}-u_{i}}{v_{2}-u_{i}}\right) & u_{i} \geq v_{3}
\end{array}\right.
\end{aligned}
$$

where $r_{j}\left(u_{i}\right)$ (or $\left.r_{i j}\right)(i=1,2, \cdots m ; j=1,2,3)$ is the membership degree of factor $u_{i}$ to the $j$ th criteria.

The fuzzy membership matrix $R$ can be expressed as:

$$
R=\left[\begin{array}{cccc}
r_{11} & r_{12} & \cdots & r_{13} \\
r_{21} & r_{22} & \cdots & r_{23} \\
\vdots & \vdots & \cdots & \vdots \\
r_{m 1} & r_{m 2} & \cdots & r_{m 3}
\end{array}\right]
$$

The fuzzy comprehensive assessment matrix $B$ was determined as:

$$
B=W \times R=\left(b_{1}, b_{2}, b_{3}\right)
$$

where $W=\left(w_{1}, w_{2}, \cdots, w_{m}\right)$ is the weight matrix; and $b_{j}(j=1,2,3)$ and is an element in matrix $B$.

In order to quantitatively reflect WECC, the evaluation grades, $v_{1}, v_{2}$ and $v_{3}$, were scored between 0 and 1: $a_{1}=0.95, a_{2}=0.5, a_{3}=0.05$. The higher score indicates that water environment protection is more effective [26].

$$
A=\sum_{j=1}^{3} b_{j} a_{j}
$$

The final assessment result $A$, represents the comprehensive index of WECC. The WECC improves with a higher index.

\section{Results}

\subsection{Weight and Descriptive Statistics of Indicators}

The general statistics of the 23 indicators as well as their corresponding weights are presented in Table 2. According to the entropy weight method, the weights of the indicators ranged from 0.0206-0.0763, and those of large weight were as follows: population density $(0.0763)>$ water resources per capita $(0.0731)>$ compliance rate for water quality standards $(0.0652)>$ water resources utility rate $(0.0622)>$ GDP per capita $(0.0555)>$ urbanization rate $(0.0534)>$ percentage of tertiary industry $(0.0526)$ $>$ wastewater treatment rate $(0.0518)>$ industrial output per capita (0.0504). Comparisons of weights demonstrated that indicators representing population as well as water quantity and quality tended to 
have greater impact on WECC. The weights of the three subsystems were as follows: 0.2282 (social subsystem), 0.4350 (environmental subsystem), 0.3268 (economic subsystem). Thus, the environmental subsystem had the most significant influence on WECC.

Table 2. The weights of 23 indicators and descriptive statistics.

\begin{tabular}{|c|c|c|c|c|c|c|c|c|c|c|c|c|}
\hline & $u_{1}$ & $u_{2}$ & $u_{3}$ & $u_{4}$ & $u_{5}$ & $u_{6}$ & $u_{7}$ & $u_{8}$ & $u_{9}$ & $u_{10}$ & $u_{11}$ & $u_{12}$ \\
\hline Maximum & 3.10 & 1259 & 82.1 & 361 & 88.1 & 834 & 153 & 31.0 & 37.0 & 55.2 & 1502 & 77.8 \\
\hline Minimum & 0.29 & 1092 & 76.4 & 266 & 64.8 & 290 & 127 & 22.0 & 35.7 & 30.0 & 675 & 56.2 \\
\hline Average & 1.47 & 1203 & 79.4 & 308 & 81.5 & 430 & 142 & 27.0 & 36.3 & 37.7 & 961 & 67.8 \\
\hline \multirow[t]{2}{*}{ Weight } & 0.0436 & 0.0763 & 0.0534 & 0.0283 & 0.0266 & 0.0731 & 0.0622 & 0.0351 & 0.0412 & 0.0225 & 0.0216 & 0.0652 \\
\hline & $u_{13}$ & $u_{14}$ & $u_{15}$ & $u_{16}$ & $u_{17}$ & $u_{18}$ & $u_{19}$ & $u_{20}$ & $u_{21}$ & $u_{22}$ & $u_{23}$ & \\
\hline Maximum & 96.3 & 2.40 & 2.40 & 14.11 & 4.64 & 59.7 & 4750 & 1.310 & 162.2 & 143.1 & 2068 & \\
\hline Minimum & 83.2 & 0.14 & 0.85 & 3.93 & 1.64 & 47.9 & 3849 & 0.590 & 36.5 & 30.4 & 1278 & \\
\hline Average & 91.4 & 1.04 & 1.48 & 8.44 & 3.10 & 53.5 & 4253 & 0.874 & 79.7 & 66.4 & 1634 & \\
\hline Weight & 0.0518 & 0.0247 & 0.0376 & 0.0555 & 0.0504 & 0.0526 & 0.0309 & 0.0463 & 0.0481 & 0.0325 & 0.0206 & \\
\hline
\end{tabular}

\subsection{Grading Criteria of Evaluation Indicators}

According to the formulas (Equations (8)-(10)), it is necessary to acquire the grading criteria of all the evaluation factors. In this study, the grading criteria in Table 3 were obtained by classification standard from relevant research [28,31], or standards including "Eco-county, eco-city, and eco-province construction standards (Revised Draft)", "Urban residents domestic water consumption standard (GB/T 50331-2016)" and "General rule for planning urban drainage engineering (GB 50318-2017)".

Table 3. Grading criteria of indicators.

\begin{tabular}{|c|c|c|c|c|}
\hline Indicator & Excellent & Moderate & Poor & Attributes \\
\hline Population growth rate & 0.3 & 0.9 & 1.5 & - \\
\hline Population density & 400 & 500 & 600 & - \\
\hline Urbanization rate & 75 & 65 & 55 & + \\
\hline Domestic water use per capita & 150 & 225 & 300 & - \\
\hline Industrial water reuse & 85 & 70 & 55 & + \\
\hline Water resources per capita & 1700 & 1100 & 500 & + \\
\hline Water resources utility rate & 40 & 50 & 60 & - \\
\hline Forest area as percent of land area & 30 & 22.5 & 15 & + \\
\hline Arable land area as percent of land area & 35 & 27.5 & 20 & + \\
\hline Use of fertilizers per unit of agricultural land area & 15 & 22.5 & 30 & - \\
\hline Use of pesticides per unit of agricultural land area & 300 & 500 & 700 & - \\
\hline Compliance rate for water quality standards & 80 & 70 & 60 & + \\
\hline Wastewater treatment rate & 95 & 90 & 85 & + \\
\hline COD emission per unit of industrial added value & 0.8 & 1.2 & 1.6 & - \\
\hline Wastewater discharge per unit of GDP & 1 & 1.5 & 2 & - \\
\hline GDP per capita & 8 & 6 & 4 & + \\
\hline Industrial output per capita & 6 & 4 & 2 & + \\
\hline The percentage of tertiary industry & 60 & 50 & 40 & + \\
\hline Annual energy consumption per capita & 3500 & 4000 & 4500 & - \\
\hline Energy consumption per unit of GDP & 0.5 & 0.95 & 1.4 & - \\
\hline Water consumption per unit of GDP & 30 & 50 & 70 & - \\
\hline Water consumption per unit of industrial added value & 25 & 40 & 55 & - \\
\hline Generation of industrial solid waste & 1200 & 1400 & 1600 & - \\
\hline
\end{tabular}

\subsection{Changes in WECC from 2006 to 2017}

The WECC and three subsystems were all divided into excellent (grade I), good (grade II) and poor (grade III) based on the calculation result. The evaluation grading criteria for WECC and subsystems in Nanjing City are shown in Table 4. 
Table 4. Grading criteria of WECC and subsystems.

\begin{tabular}{cc}
\hline Grade & Comprehensive Index \\
\hline excellent (I) & 0.725 \\
moderate (II) & 0.55 \\
poor (III) & 0 \\
\hline
\end{tabular}

The comprehensive index in Nanjing from 2006 to 2017 was calculated based on the fuzzy comprehensive evaluation method combined with the entropy weight of each indicator, as shown in Figure 2. WECC in Nanjing exhibited a general growth trend but did not exceed the moderate grade (II). WECC increased from 0.3045 in 2006 to 0.5302 in 2017, and the average rate of change was approximately $2.05 \%$ per year. It could be interpreted that the level of sustainable development was better during these years, but Nanjing's speed of social, environmental, and economic development was not high enough. The comprehensive index fell in 2011 and 2016. This moderate fluctuation in the long-term period means that the short-run WECC is volatile to external shocks [37].

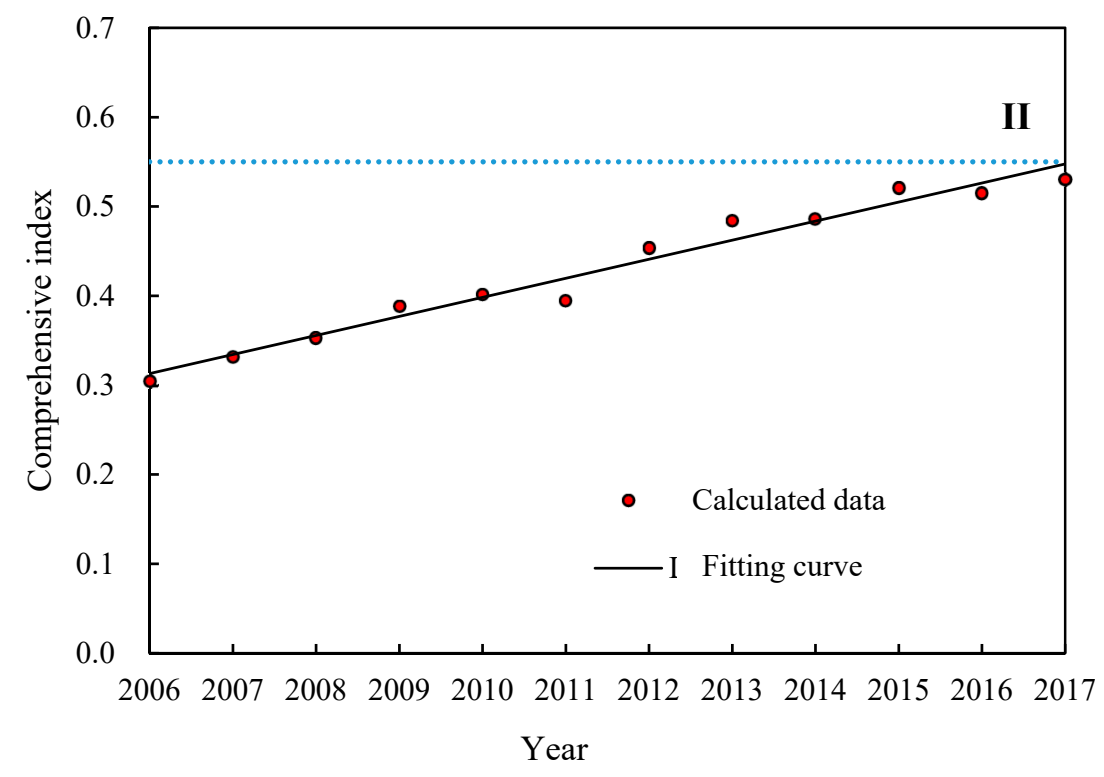

Figure 2. Comprehensive index of WECC in 2006-2017.

Figure 3 shows the comprehensive index and variation of each subsystem in Nanjing from 2006 to 2017. Specifically, the social, environmental and economic subsystems increased by $29.3 \%, 83.1 \%$ and $97.2 \%$ respectively. In comparison, the comprehensive index of the economic subsystem displayed an increasing tendency throughout the study period; it surpassed the moderate grade (II) in 2013. The highest point (0.6199) of the economic subsystem appeared in 2017, whereas the lowest value was 0.3143 in 2006 . The social subsystem increased slightly from $0.3438-0.4445$ in $2006-2017$. There were some fluctuations in this subsystem, and the largest slump was observed in 2011. The environmental subsystem exhibited a strong upward trend but was still lower than grade II. The highest point was 0.5057 in 2017, whereas the lowest was 0.2763 in 2006. Overall, Nanjing has a solid economic foundation, but the social and environmental subsystems must be strengthened. 


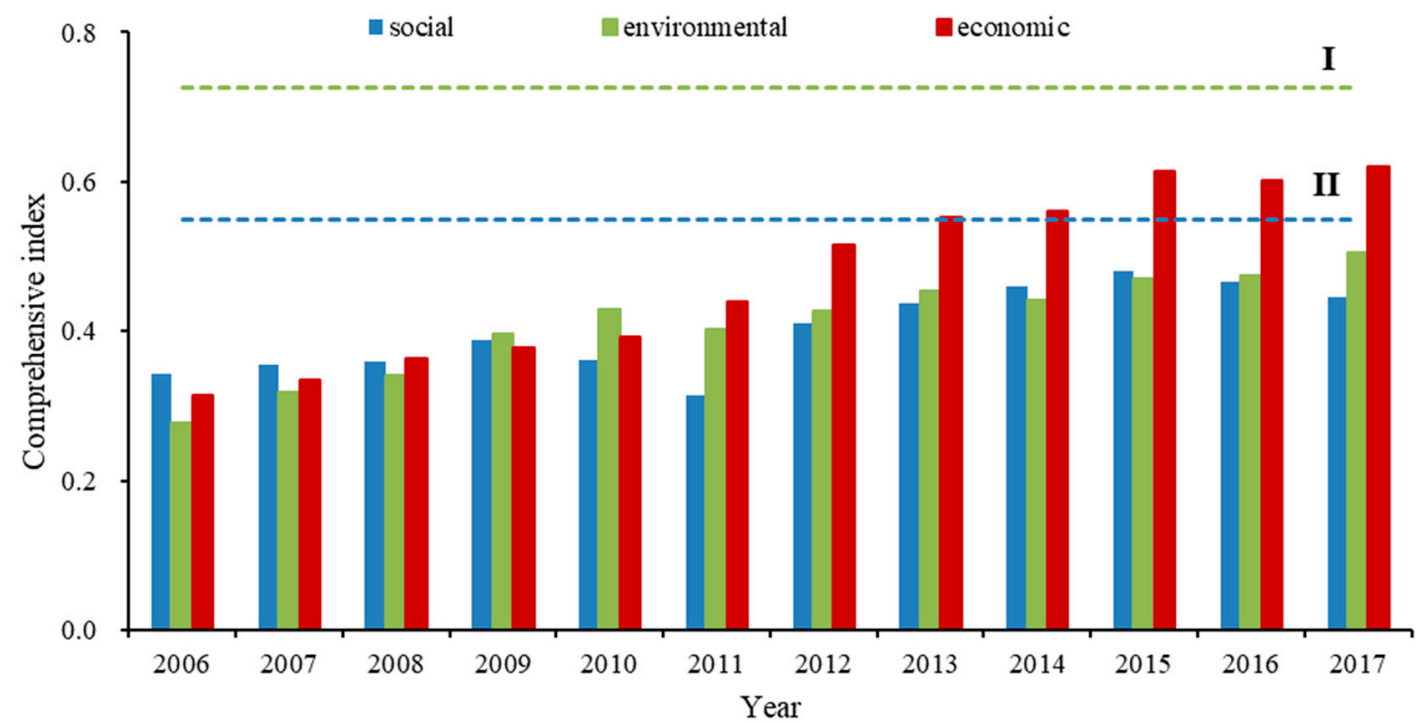

Figure 3. Comprehensive index of the three subsystems in 2006-2017.

\subsection{Evaluation of Indicators from 2006 to 2017}

In the evaluation of single indicators, the higher the comprehensive index, the more beneficial to sustainable development. For a positive indicator, the comprehensive index changes in the same direction as the indicator value; for the negative indicator, the index and indicator value change inversely. The evaluation results of the indicators are shown in Figure 4 for the three subsystems in 2006-2017.

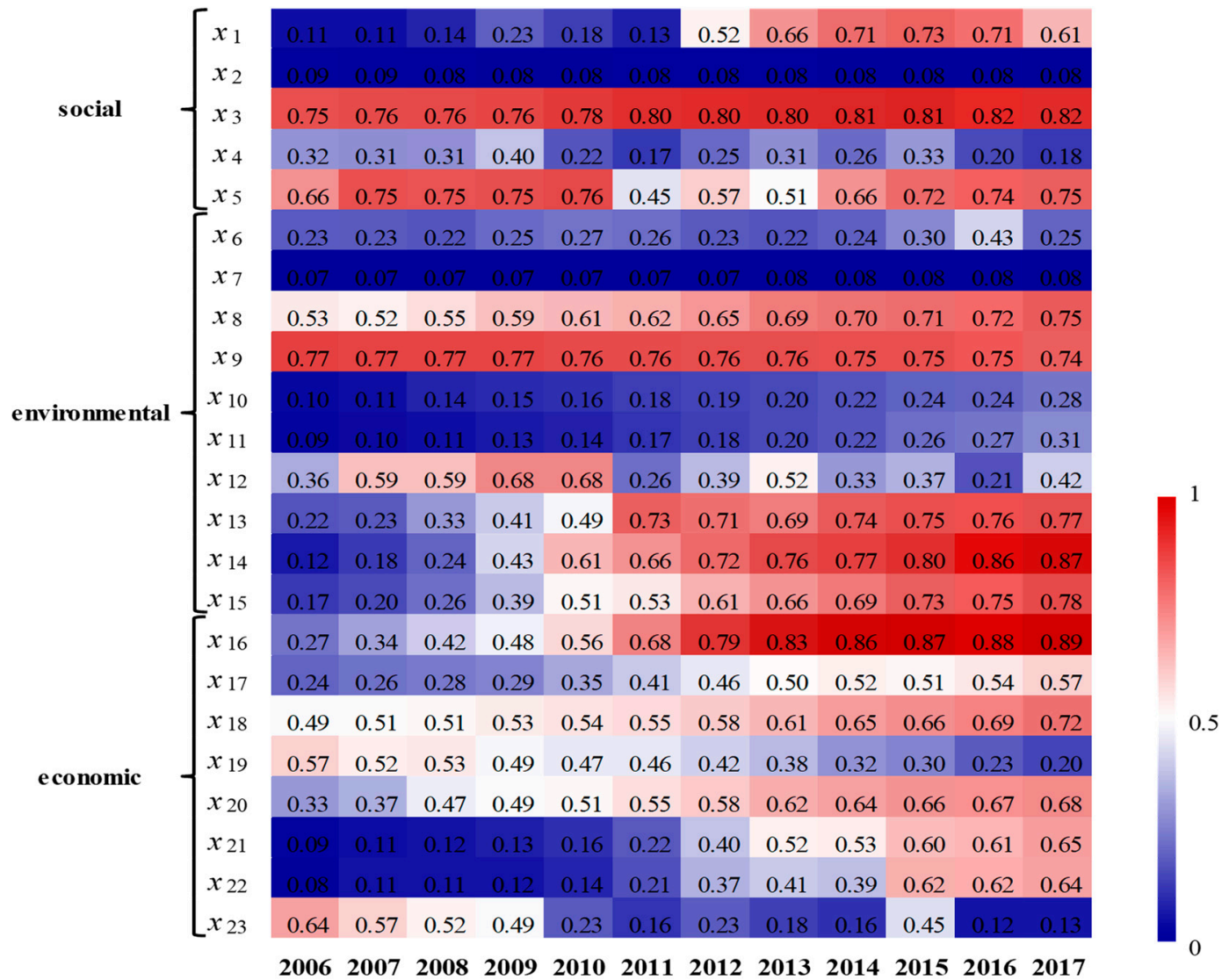

Figure 4. Comprehensive index of indicators in 2006-2017. 


\subsubsection{Social Subsystem}

In terms of the social subsystem, the population density $\left(u_{2}\right)$ exhibited consistently low indexes in 2006-2017 owing to the large population immigrating to Nanjing. Increased economic strength and more additional job options in recent years, along with the improved infrastructure, stimulated a population shift from economically backward areas to more developed regions. Although the total population grew, the growth rate declined by $81 \%$ from 2006 to 2017. Thus, the comprehensive indexes of population growth rate $\left(u_{1}\right)$ increased significantly from 0.11 in 2006 to 0.61 in 2017 . The urbanization rate $\left(u_{3}\right)$ performed strongly with a comprehensive index of more than 0.75 throughout the period. The comprehensive index of domestic water use per capita $\left(u_{4}\right)$ remained low especially in 2011. Industrial water reuse $\left(u_{5}\right)$ behaved well in most of the years, but a low point was also observed in 2011. This implies that industrial water reuse and domestic water consumption played an important role in the trough in the social subsystem. Overall, the variability introduced by the slowdown in population growth was the primary driving force for the increase in the figures for the social subsystem. The results also indicated that dense population and overuse of domestic water prevented further growth of the social subsystem.

\subsubsection{Environmental Subsystem}

For the environmental subsystem, the comprehensive index of indicators representing forest area, wastewater treatment and pollution control $\left(u_{8}, u_{13}, u_{14}\right.$ and $\left.u_{15}\right)$ showed consistent growth and all reached high levels (more than 0.75 in 2017). This was caused by the effective application of environmental laws and a variety of actions taken by the government to protect the environment. For instance, fewer fertilizers and pesticides were used in agricultural land, which can be ascertained from the performance of the two indicators $\left(u_{10}\right.$ and $\left.u_{11}\right)$. However, pollution discharge increased, especially in recent years as the population continued to rise and industrialization accelerated. This led to a large decline in compliance rate for water quality standards $\left(u_{12}\right)$ in 2011-2017. Regarding the indicators related to water resources $\left(u_{6}\right.$ and $\left.u_{7}\right)$, the comprehensive indexes were lower than 0.45 and 0.10 , respectively. This minimal improvement in the two indicators was especially influential, given that those indicators accounted for $31 \%$ of the environmental subsystem. Thus, water shortage, over-exploitation of water resources, and poor water quality were likely to be the dominant factors in constraining the growth of environmental subsystems in Nanjing from 2006 to 2017. The results of the indicator analysis also demonstrated that local government tried to protect the water environment; however, the forces of environmental destruction (e.g., socioeconomic, demographic and technological) overwhelmed protection efforts [38].

\subsubsection{Economic Subsystem}

In the economic subsystem, GDP per capita $\left(u_{16}\right)$, industrial output per capita $\left(u_{17}\right)$ and percentage of tertiary industry $\left(u_{18}\right)$ exhibited a strongly increasing trend. This was because Nanjing's economic growth in the past decades has been one of the fastest among major cities in China, a more than $10 \%$ annual increase in most years, and industrial structure has somewhat upgraded. The comprehensive index of annual energy consumption per capita $\left(u_{19}\right)$ decreased to 0.20 , whereas the index of energy consumption per unit of GDP (energy intensity) $\left(u_{20}\right)$ has increased to 0.68 . This was because, although the highest energy demand in history was driven by the economy and population, the governmental target for reducing energy intensity in its energy-conservation plan was nonetheless achieved. Indicators associated with economic water consumption $\left(u_{21}, u_{22}\right)$ both decreased by nearly $80 \%$, which resulted in an improvement of their comprehensive index. The index for generated industrial solid waste $\left(u_{23}\right)$ showed an irregular fluctuation with a decreasing trend through time, indicating that there was a great increase in urban solid waste. The analysis results suggested that high levels of energy consumption and industrial solid waste generation are major problems in this subsystem. Economic 
growth, energy and water use intensity reduction led to a large overall increase in the figures for the economic subsystem in Nanjing across the entire study period.

\section{Discussion}

\subsection{Problems Underlying Changes in WECC}

Nanjing's WECC presents a continuous increasing tendency from 2006 to 2017, while the increase rate remains slow. The evaluation of indicators provides an explanation for the variation of WECC and the three subsystems and helps to reveal the underlying problems of WECC.

In the social subsystem, the dense population inevitably exerts great impacts on WECC. In 2019, the population density of Nanjing reached 1290 people $/ \mathrm{km}^{2}$. Population gains are driven largely by migration. Nanjing is urbanized, with 6.82 million people or $82 \%$ living in urban areas. Although the city has benefited from its massive population, especially in terms of economic growth, it also faces major challenges. For example, local water resources per capita in Nanjing are less than $1000 \mathrm{~m}^{3}$, which is no more than $1 / 8$ of the world's average. In addition, domestic water consumption increased by 34.3\% during 2006-2017. If an abundant transit of water brought by the Yangtze River is not achieved, water shortage will be one of the future bottlenecks within the city [39]. The ever-expanding population will also affect Nanjing's already troublesome land degradation and water environment [40]. Nanjing lost 8110 ha arable land between 2006 and 2017 under urbanization. To ensure its food supply, Nanjing has attempted to intensify the use of land, which has consequently contributed to land degradation. Domestic wastewater increased by nearly $60 \%$, and population growth is also viewed as one of the decisive factors.

In the economic subsystem, service industries comprised the largest part of Nanjing's GDP, while manufacturing industries accounted for $38 \%$ in 2019. Comparatively ten years ago, manufacturing industries were dominant in the overall composition of GDP. Nevertheless, despite the rapid development of service industries catching up quickly, major industries including petroleum, cement, steel and electric power still constituted approximately 35\% of the industrial output value and covered more than $90 \%$ of the total emission of industrial pollutants. Because of its reliance on heavy industry, Nanjing's development has been accompanied by environmental degradation as those industries at the low end of the global value chain are energy-, resource- and pollution-intensive. Although local government announced plans to accelerate the transformation of industrial restructuring and development patterns, the proportion of pollution-intensive industries decreased only by little. This effect may be attributed to the composition of GDP, which has a strong production component and an over-reliance on investment. For years, China's central and local governments have been enthusiastic about investing in infrastructure to boost growth when the economy is vulnerable, which will directly increase the consumption of heavy industry products, thus resulting in an overcapacity problem in heavy industry [41]. This development pattern may lead to destructive ecological and environmental consequences [42].

In the environmental subsystem, the compliance rate for water quality standards in Nanjing remained lower than $80 \%$. Moreover, pollution emissions still showed an upward tendency: wastewater discharge increased by $46.8 \%$, and industrial solid waste increased by $56.2 \%$ from 2006 to 2017 . Although Nanjing has attempted to protect the environment as claimed in its 11th, 12th and 13th Five-Year Plan, it is also pursuing rapid growth in GDP. Heavily polluting factories are still built at a rapid rate [43]. A key challenge for Nanjing is to continue strong economic growth while reversing environmental degradation. Reductions in pollutant emissions per unit of GDP are unlikely to reduce total emissions if the economy continues to grow [44]. Local governments must ensure efficient enforcement of environmental laws when they conflict with economic development. However, the main problem seems to be the inability to enforce most of the environmental regulations when facing overwhelming economic requirements [45]. 


\subsection{Policy Suggestion}

To improve WECC effectively, specific and targeted policy suggestions are proposed as follows:

(1) Strict enforcement of environmental regulations

Addressing water pollution in Chinese cities requires strategic urban planning and regulations [46]. The implementation of environmental policy objectives is also an important source for improving the overall WECC. Lax enforcement and competing policy objectives will undercut the government's efforts to avoid environmental problems. Local government should determine the balance between economic growth and environmental protection objectives and strengthen incentives to enforce environmental regulations on firms.

(2) Spatial arrangement of the urban population

Nanjing continues to encourage population growth in newly-approved plans to achieve a prosperous society. However, Nanjing's dense population places significant pressure on WECC. According to statistics, downtown residents comprise more than half of the city's population. A reasonable population distribution is needed. Nanjing should create new towns with well-developed public services including pensions, health care, and compulsory education, which would allow for more people to move from downtown. The environmental and social problems caused by overcrowding may thus be effectively alleviated.

\section{(3) Transformation of the development model}

Rapid growth in GDP has been Nanjing's central goal during the past decades. The dominant development model has achieved high GDP with low resource efficiency and high pollution. Nanjing must shift its economic development model toward efficient resource use and low pollution, which can greatly improve the local WECC. Additional efforts should be made to reduce the role of infrastructure investment in spurring growth, which has proven to be more pollution-intensive [38]. Fortunately, the Chinese government has proposed a "New Normal" economic development concept and has strongly emphasized development quality and a reasonable economic structure to prevent and mitigate pollution [42]. In line with this concept, the Nanjing government should develop more environmentally beneficial technologies, which would increase economic efficiency while reducing environmental damage [38].

\section{(4) Optimization of the industrial structure}

The transformation of industrial structure is the key factor in promoting WECC by increasing the percentage of tertiary industry and reducing pollutant emissions. Nanjing should continue to promote the upgrading of industrial structures. The government needs to accelerate the development of the service sector and high-tech industry and focus on innovation while restricting the rapid growth of energy-intensive and pollutant-intensive industries, such as steel, cement, chemicals and power plants. If these policies are carefully implemented, a more sustainable city is entirely possible.

\section{Conclusions}

The following conclusions can be drawn from the work described in this paper:

(1) Based on the carrying capacity concept, this study constructed a hierarchical evaluation indicator system including three system layers (social, environmental and economic subsystems), and determined grading criteria to provide a reference for WECC assessment.

(2) The WECC comprehensive index of Nanjing increased from 0.3045-0.5302 in 2006-2017, approaching Grade II (moderate) with a slow growth rate. The economic subsystem presented a stable and continuous growth, whereas the social and environmental subsystems were under considerable pressure. 
(3) Factors improving WECC include slow population growth, improved water environment protection, rapid economic growth, and reduced energy and water use intensity. Factors blocking WECC include increased population density, excessive water consumption, degraded water quality and an unsustainable economic development pattern.

(4) To resolve the primary problems of WECC under urbanization, practical suggestions are proposed from the aspects of population, environmental regulation enforcement, development patterns and industrial structure.

Author Contributions: Conceptualization, Z.X., C.D. and S.X.; software, Q.D.; validation, X.L. and B.Y.; formal analysis, Z.X.; investigation, Z.X., C.D. and Z.Z.; resources, S.X.; data curation, Z.X.; writing-original draft preparation, Z.X.; writing-review and editing, C.D.; visualization, Q.D.; supervision, X.L. and S.X.; project administration, C.D. and X.L.; funding acquisition, S.X. All authors have read and agreed to the published version of the manuscript.

Funding: The authors gratefully acknowledge the financial supports from Major Science and Technology Program for Water Pollution Control and Treatment (No. 2018ZX07601-001, 2017ZX0702004-005), and National Key Research and Development Program of China (No.2016YFC0401303).

Conflicts of Interest: The authors declare no conflict of interest.

\section{References}

1. Xiao, R.; Wang, G.; Zhang, Q.; Zhang, Z. Multi-scale analysis of relationship between landscape pattern and urban river water quality in different seasons. Sci. Rep. 2016, 6, 25250. [CrossRef] [PubMed]

2. Wang, S.J.; Ma, H.; Zhao, Y.B. Exploring the relationship between urbanization and the eco-environmentA case study of Beijing-Tianjin-Hebei region. Ecol. Indic. 2014, 45, 171-183. [CrossRef]

3. Li, Y.; Jia, L.; Wu, W.; Yan, J.; Liu, Y. Urbanization for Rural Sustainability Rethinking China's Urbanization Strategy. J. Clean. Prod. 2018, 178, 580-586. [CrossRef]

4. Liu, J.; Yang, W. Water sustainability for China and beyond. Science 2012, 337, 649-650. [CrossRef] [PubMed]

5. Lu, Y.; Zhang, Y.; Cao, X.; Wang, C. Forty years of reform and opening up: China's progress toward a sustainable path. Sci. Adv. 2019, 5, eaau9413. [CrossRef]

6. Wang, S.; Xu, L.; Yang, F.; Wang, H. Assessment of water ecological carrying capacity under the two policies in Tieling City on the basis of the integrated system dynamics model. Sci. Total Environ. 2014, 472, 1070-1081. [CrossRef]

7. Ehrlich, P.R.; Holdren, J.P. Impact of population growth. Science 1971, 171, 1212-1217. [CrossRef]

8. Meadows, D.H.; Meadows, D.L.; Randers, J.; Behrens, W.W. The limits to growth: A report for the Club of Rome's project on the predicament of mankind. Demography 1973, 10, $289-299$.

9. Baldwin, J.H. Environmental Planning and Management; Westview Press: Boulder, CO, USA, 1985.

10. De La Sen, M.; Alonso-Quesada, S. Control issues for the Beverton-Holt equation in ecology by locally monitoring the environment carrying capacity: Non-adaptive and adaptive cases. Appl. Math. Comput. 2009, 215, 2616-2633. [CrossRef]

11. Dang, X.; Liu, G. Emergy measures of carrying capacity and sustainability of a target region for an ecological restoration programme: A case study in Loess Hilly Region, China. J. Environ. Manag. 2012, 102, 55-64. [CrossRef]

12. Dou, M.; Ma, J.; Li, G.; Zuo, Q. Measurement and assessment of water resources carrying capacity in Henan Province, China. Water Sci. Eng. 2015, 8, 102-113. [CrossRef]

13. Wang, C.; Hou, Y.; Xue, Y. Water resources carrying capacity of wetlands in Beijing: Analysis of policy optimization for urban wetland water resources management. J. Clean. Prod. 2017, 161, 1180-1191. [CrossRef]

14. Jia, Z.; Cai, Y.; Chen, Y.; Zeng, W. Regionalization of water environmental carrying capacity for supporting the sustainable water resources management and development in China. Resour. Conserv. Recycl. 2018, 134, 282-293. [CrossRef]

15. Meng, C.; Du, X.; Ren, Y. Sustainable urban development: An examination of literature evolution on urban carrying capacity in the Chinese context. J. Clean. Prod. 2020, 277, 122802. [CrossRef] 
16. Peng, T.; Deng, H. Comprehensive evaluation for sustainable development based on relative resource carrying capacity-A case study of Guiyang, Southwest China. Environ. Sci. Pollut. Res. 2020, 27, 20090-20103. [CrossRef]

17. Wang, Y.; Wang, Y.; Su, X. Evaluation of the comprehensive carrying capacity of interprovincial water resources in China and the spatial effect. J. Hydrol. 2019, 575, 794-809. [CrossRef]

18. Lei, K.; Zhou, S. Per capita resource consumption and resource carrying capacity: A comparison of the sustainability of 17 mainstream countries. Energy Policy 2012, 42, 603-612. [CrossRef]

19. David, G.S.; Carvalho, E.D.; Lemos, D.; Silveira, A.N.; Dall'Aglio-Sobrinho, M. Ecological carrying capacity for intensive tilapia (Oreochromis niloticus) cage aquaculture in a large hydroelectrical reservoir in Southeastern Brazil. Aquac. Eng. 2015, 66, 30-40. [CrossRef]

20. Murilloalvarado, P.E.; Guilléngosálbez, G.; Ponceortega, J.M.; Castromontoya, A.J.; Sernagonzález, M.; Jiménez, L. Multi-objective optimization of the supply chain of biofuels from residues of the tequila industry in Mexico. J. Clean. Prod. 2015, 108, 422-441. [CrossRef]

21. Ye, F.; Park, J.; Wang, F. Analysis of Early Warning Spatial and Temporal Differences of Tourism Carrying Capacity in China's Island Cities. Sustainability 2020, 12, 1328. [CrossRef]

22. He, Y.; Xie, H. Exploring the spatiotemporal changes of ecological carrying capacity for regional sustainable development based on GIS: A case study of Nanchang City. Technol. Forecast. Soc. Chang. 2019, 148, 119720. [CrossRef]

23. Lu, Y.; Xu, H.; Wang, Y.; Yang, Y. Evaluation of water environmental carrying capacity of city in Huaihe River Basin based on the AHP method: A case in Huai'an City. Water Resour. Ind. 2017, 18, 71-77. [CrossRef]

24. Zhang, J.; Zhang, C.; Shi, W.; Fu, Y. Quantitative Evaluation and Optimized Utilization of Water Resources-Water Environment Carrying Capacity based on Nature-Based Solutions. J. Hydrol. 2018, 568, 96-107. [CrossRef]

25. Yang, Z.; Song, J. Comprehensive evaluation and scenario simulation for the water resources carrying capacity in Xi'an city, China. J. Environ. Manag. 2019, 230, 221-233. [CrossRef] [PubMed]

26. Chi, M.; Zhang, D.; Fan, G. Prediction of water resource carrying capacity by the analytic hierarchy process-fuzzy discrimination method in a mining area. Ecol. Indic. 2019, 96, 647-655. [CrossRef]

27. Forio, M.A.E.; Mouton, A.; Lock, K. Fuzzy modelling to identify key drivers of ecological water quality to support decision and policy making. Environ. Sci. Policy 2017, 68, 58-68. [CrossRef]

28. Wu, X.; Hu, F. Analysis of ecological carrying capacity using a fuzzy comprehensive evaluation method. Ecol. Indic. 2020, 113, 106243. [CrossRef]

29. Xie, T.; Wang, M.; Chao, C. Evaluation of the natural attenuation capacity of urban residential soils with ecosystem-service performance index (EPX) and entropy-weight methods. Environ. Pollut. 2018, 238, 222-229. [CrossRef]

30. Niccolucci, V.; Galli, A.; Reed, A.; Neri, E.; Wackernagel, M.; Bastianoni, S. Towards a 3D National Ecological Footprint Geography. Ecol. Model. 2011, 222, 2939-2944. [CrossRef]

31. Shao, Q.; Liu, X.; Zhao, W. An alternative method for analyzing dimensional interactions of urban carrying capacity: Case study of Guangdong-Hong Kong-Macao Greater Bay Area. J. Environ. Manag. 2020, 273, 111064. [CrossRef]

32. Wang, J.; Wei, X.; Guo, Q. A three-dimensional evaluation model for regional carrying capacity of ecological environment to social economic development: Model development and a case study in China. Ecol. Indic. 2018, 89, 348-355. [CrossRef]

33. Sun, L.; Miao, C.; Yang, L. Ecological-economic efficiency evaluation of green technology innovation in strategic emerging industries based on entropy weighted TOPSIS method. Ecol. Indic. 2017, 73, 554-558. [CrossRef]

34. Wang, G.; Liu, Y.; Hu, Z. Flood Risk Assessment Based on Fuzzy Synthetic Evaluation Method in the Beijing-Tianjin-Hebei Metropolitan Area, China. Sustainability 2020, 12, 1451. [CrossRef]

35. Chiu, R.H.; Lin, L.H.; Ting, S.C. Evaluation of Green Port Factors and Performance: A Fuzzy AHP Analysis. Math. Probl. Eng. 2014, 5, 1-12. [CrossRef]

36. Zhu, R.; Liang, Q.; Zhan, H. Analysis of Aero-engine Performance and Selection Based on Fuzzy Comprehensive Evaluation. Procedia Eng. 2017, 174, 1202-1207. [CrossRef]

37. Sun, C.; Chen, L.; Tian, Y. Study on the urban state carrying capacity for unbalanced sustainable development regions: Evidence from the Yangtze River Economic Belt. Ecol. Indic. 2018, 89, 150-158. [CrossRef] 
38. Liu, J.; Diamond, J. Revolutionizing China's Environmental Protection. Science 2008, 319, 37-38. [CrossRef]

39. Lu, Y.; Jenkins, A.; Ferrier, R.C.; Bailey, M.I.; Gordon, J.; Song, S.; Huang, J.; Jia, S.; Zhang, F.; Liu, X. Addressing China's grand challenge of achieving food security while ensuring environmental sustainability. Sci. Adv. 2015, 1, e1400039. [CrossRef]

40. Peng, X. China's Demographic History and Future Challenges. Science 2011, 333, 581-587. [CrossRef]

41. Gao, J.; Tang, X.; Ren, H.; Cai, W. Evolution of the Construction Industry in China from the Perspectives of the Driving and Driven Ability. Sustainability 2019, 11, 1772. [CrossRef]

42. Zhang, W.; Wang, J.; Zhang, B.; Bi, J.; Jiang, H. Can China Comply with Its 12th Five-Year Plan on Industrial Emissions Control: A Structural Decomposition Analysis. Environ. Sci. Technol. 2015, 49, 4816-4824. [CrossRef] [PubMed]

43. Wu, J.; Dennis, Y.; Wen, W. Environmental regulations and redistribution of polluting industries in transitional China: Understanding regional and industrial differences. J. Clean. Prod. 2019, 126, 142-155. [CrossRef]

44. Peters, G.P.; Guan, D.; Hubacek, K.; Minx, J.; Weber, C.L. Effects of China's Economic Growth. Science 2010, 328, 824-825. [CrossRef]

45. Li, L.; Liu, B. Research on the Relationship between Economy Growth and Environmental Pollution in Shandong Province - The Empirical Research from 1981 to 2009. Adv. Mater. Res. 2012, 524-527, 3433-3437. [CrossRef]

46. Wang, Z.; Chen, J.M. A Greener Future for China's Cities. Science 2010, 327, 1199. [CrossRef] [PubMed]

Publisher's Note: MDPI stays neutral with regard to jurisdictional claims in published maps and institutional affiliations. 